\title{
The U-PHOS experience within the ESA student REXUS/BEXUS programme: a real space hands-on opportunity
}

Pietro Nannipieri, Martina Anichini, Lorenzo Barsocchi, Giulia Becatti, Luca Buoni, Andrea Catarsi, Federico Celi, Paolo Di Giorgio, Paolo Fattibene, Eugenio Ferrato, Pietro Guardati, Edoardo Mancini, Gabriele Meoni, Federico Nesti, Stefano Piaquadio, Edoardo Pratelli, Lorenzo Quadrelli, Alessandro Simone Viglione, Francesco Zanaboni, Carlo Bartoli, Paolo Di Marco, Salvo Marcuccio, Roberto Di Rienzo, Luca Fanucci, Federico Baronti, Mauro Mameli, Sauro Filippeschi

University of Pisa, Italy

pietro.nannipieri@ing.unipi.it

Marco Marengo

University of Brighton, United Kingdom

\begin{abstract}
U-PHOS (Upgraded PHP Only for Space) is a project developed by a team of students from the University of Pisa with the goal to analyze and characterize the behavior of a Pulsating Heat Pipe (PHP), one of the most attractive two phases passive systems for thermal management in space applications. The PHP consists of a sealed serpentine capillary tube filled with a working fluid. The heat is efficiently transported by means of the combined action of phase change and capillary forces, so no extra equipment is required. The project aims at investigating the thermal response of such a device under a milli-gravity condition, in order to assess its effectiveness in space conditions. U-PHOS is one of the selected experiment of the REXUS/BEXUS programme, which allows European university students to carry out scientific and technical experiments on research rockets and balloons, thanks to a bilateral agency agreement between the German Aerospace Centre (DLR) and the Swedish National Space Board (SNSB) in collaboration with ESA. 19 students from the University of Pisa, with different backgrounds, compose the U-PHOS team. Students had the chance to completely design, build and test the experiment, which will flight up to space in March 2017. This paper intends to describe the work done by the students, their organization and how this experience empowered their careers, from both an academic and professional point of view.
\end{abstract}

Keywords- U-PHOS, PHOS, PHP, REXUS/BEXUS, STUDENT PROJECT, SOUNDING ROCKET, PISA

\section{INTRODUCTION}

\section{A. REXUS/BEXUS as a learning enviroment}

It is no news that, over the years, a college student must acquire many additional capabilities in order to be a relevant candidate for qualified jobs. For a student, in order to satisfy these requirements, it became fundamental to start with the improvement of professional and interpersonal skills, such as collaboration in a team, attitude for problem solving, capabilities of managing relations with co-workers and the ability to have good communication skills in every situation. These improvements may be fostered by projects out of students' university plans [1]. The programme aims to learn and develop these particular skills [2]-[4]. The REXUS/BEXUS programme allows students from universities and higher education colleges across Europe to carry out scientific and technological experiments on research rockets and balloons. Each year, two rockets and two balloons are launched, carrying up to twenty experiments designed and built by student teams.
As part of the ESA Education, the REXUS/BEXUS programme aims at helping young Europeans to gain and maintain an interest in science and technology, by designing and manufacturing their own experiment. In this way, students could have the possibility to face problems coming from a real space mission with all the constraints it may have (i.e., structural problems from rocket vibrations, microgravity environment, creation of hardware suitable for low-weight and small assembly and so on). Students have to comply with several "deadlines" known as milestones.

\section{B. U-PHOS Project}

U-PHOS is one of the selected experiment of the REXUS/BEXUS programme, cycle 9. It is an upgrade of the PHOS project [5], which took part in the programme two years ago. The scientific goal of both projects is the same: investigating the behavior of a high performance thermal device suitable for space applications, the Pulsating Heat Pipe (PHP, Fig. 1). U-PHOS aims at improving all the PHP subsystems, starting from its configuration - to be more compact and powerful - including the acquisition system, which will incorporate the cutting-edge technology of Fiber Bragg Grating (FBG) temperature sensors, and ending with the electronic components, essential to manage and coordinate all the

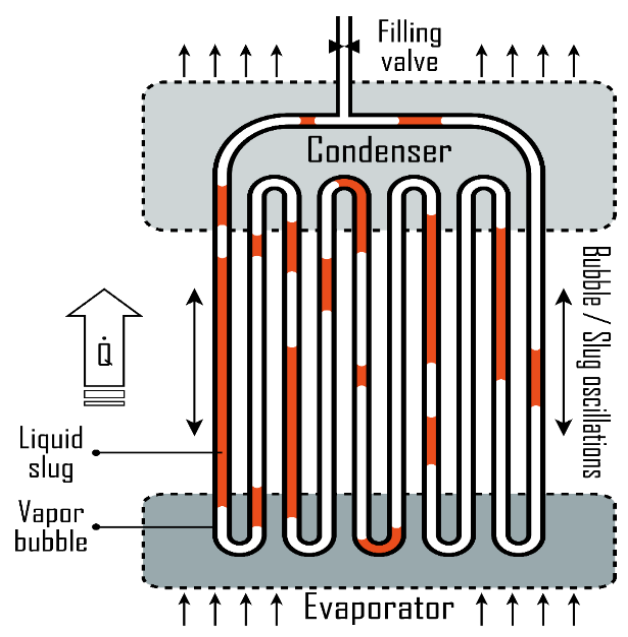

Fig. 1. PHP Working principles. 
experiment tasks. In more detail, the PHP is provided with a constant heat source, powered by a space-approved battery. The heat will be dissipated on an innovative heat sink, never tested before in milli-gravity condition, formed by a phase change material (paraffin) combined with an aluminum metallic foam, to obtain an optimized ratio between heat capability and weight. Finally, the experiment will measure temperatures and pressures, in order to calculate the device thermal-hydraulic response to the occurrence of milli-gravity.

\section{THE TEAM}

\section{A. Recruitement}

The Team consists of 19 members, divided into 6 sub-teams, each of them responsible for a specific area of the experiment: Mechanics, Thermal Analysis, Electronics, Software, Outreach and Test/Integration. Three members come from the previous PHOS project and one of them was appointed as Team Leader and Project Manager. Other members have been selected in two separate recruiting days opened to all students of the University of Pisa. In particular, after a preliminary period of advertising, by using social media and University web platforms, the enrollment consisted of two stages, due to the high number of candidates. First, tentative candidates have been pre-selected by means of an electronic application form, where they could describe themselves, their skills and what they expected from the project.

The number of candidates was 44 in the first selection and 513 in the second one. In the first recruiting, which built up the majority of the team, 11 team members were selected with an acceptance rate of $25 \%$, while in the second one only 5 position were available, resulting in an acceptance rate lower than $1 \%$. These numbers witness the interest created around the project during its developing. In the end, the team was composed of 19 team members, 17 of them coming from the engineering school, 1 from economics and 1 from physics.

\section{B. Organisation}

As described in the paragraph above, U-PHOS project involves a high number of members with different roles and skills, working all together. Owing to that, it has been decided to have a member responsible exclusively of the project management. Because of the project complexity, professional methods and software were used, in order to accomplish all the specific requirements and to ease the work: a dedicated management software has been used to create the budget plan, the Gantt diagram and the project Work Breakdown Structure (Fig. 2), like Microsoft Excel and Microsoft Project. The project is divided into five main work packages that include all the tasks: every work package has a well-defined responsible. Almost every team member is also carrying out her/his studies, therefore the time dedicated to U-PHOS project has to be planned carefully. All the sub-teams nominated a responsible in order to optimize coordination and communication inside the team. A weekly meeting of the work package leaders is performed while a full team meeting is held approximately once a month. This gives non-lead members extra time saved from weekly meeting to work on the project. To efficiently communicate the team has been using a dedicated application: Slack. It is a web platform

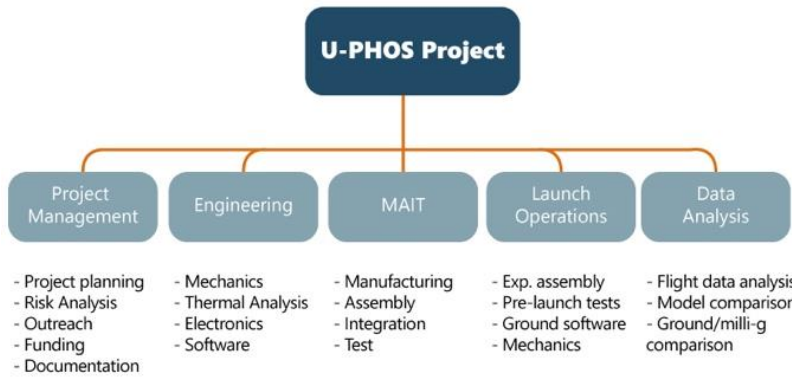

Fig. 2. High Level Work Breakdown Structure

for team working: it runs on computer and smartphones and makes it possible to set up a more direct and efficient communication channel. Slack allows team channels to be created. The channels can be public or private: we set a channel for each team in order to have a single place where we can share information, files and updates. This is useful since it lets us specify a precise schedule of the usage of laboratories and equipment.

\section{Budget}

U-PHOS experiment, as any other research experiment, requires high quality and expensive components, as well as manufacturing processes: the purchasing of such components is, in fact, the main cost item in our budget. Figure 4 shows the composition of the expenditure budget, in which the elements needed to build the experiment are highlighted: with an amount of nearly $€ 58.000$, they represent the major part of the expenditure, considering a reasonable margin to cover risks that may occur (Fig 3). The project have financial support from University of Pisa and other institutional funds but these ones are not enough to cover the budget, thus other resources has been found: Sponsors and Crowdfunding. The hardest part in finding sponsors consists in underlining the importance and the resonance that this research project could give them.

We have also started a crowdfunding campaign to enlarge our resources dedicated to the logistics, in order to give the

\section{EXPENDITURE BUDGET}



Fig. 3. Expenditure Budget 
possibility to all team members to attend the launch campaign, which is fundamental for the success of the experiment. The critical issue of crowdfunding a research project is explaining the importance of backing and supporting scientific research. The campaign is now ongoing, thus final data are not available yet. Table I shows the sponsors and institutions supporting us and highlights the final total resources available to the project. Within the sponsorship field, we also considered the support given by ESA to reduce our trip expenditures by $€ 12.880$. Not only did sponsors give us support in financial terms, but they also provided us with materials and manufacturing for free, as well as consulting. The return they have is not only in terms of visibility through media, but also in creating a network with young and bright engineering students.

\section{EDUCATIONAL ASPECTS AND CAREER BOOSTING}

\section{A. Key facts}

Being an experiment of REXUS/BEXUS programme, UPHOS is an opportunity for students to work in a space project observing the strict standards of the space engineering. Project planning and implementation follow a simplified version of the ECSS standards [9], which consist in providing an introduction and overview of the typical major tasks, associated review milestones and objectives for each of the phases in a project life cycle. The experiment had to overcome the following reviews, within the timing shown in Fig. 4:

- Proposal Presentation: in order to have the experiment selected amongst others, the team had to present it to a board of space professionals and to demonstrate its feasibility and scientific relevance.

- $\quad$ Preliminary design Review (PDR): the team had to explain and discuss its design with a board of space specialists from different space agencies.

- Critical Design Review (CDR): the team had to explain the experiment final design with a board of specialists in order to have it approved.

- Integration Progress Review (IPR): the team had to show the progress of integration and testing to the rocket payload manager.

- Experiment Acceptance Review (EAR): the team had to present the completed experiment and to test it in front of the payload manager of the rocket, in order to obtain the ticket for the launch.

Besides an important scientific role, U-PHOS allows the team members to increase and improve their skills. The team
TABLE I. U-PHOS FUNDING

\begin{tabular}{|lcr|}
\hline \multicolumn{1}{|c}{ SPONSORS } & $\%$ & \multicolumn{1}{c|}{$€$} \\
\hline Infibra \& SmartFibres & $18 \%$ & $10.500 €$ \\
Aavid & $4 \%$ & $2.375 €$ \\
Elemaster & $3 \%$ & $2.000 €$ \\
Vicor & $1 \%$ & $750 €$ \\
Peri Elettronica & $0 \%$ & $100 €$ \\
ESA & $22 \%$ & $12.880 €$ \\
Sportika & $0 \%$ & $250 €$ \\
Rotary Galilei Pisa & $3 \%$ & $1.500 €$ \\
Meccanocar & $0 \%$ & $200 €$ \\
Bank of Lajatico & $1 \%$ & $500 €$ \\
\hline Total sponsors & $53 \%$ & $\mathbf{3 1 . 0 5 5} €$ \\
\hline ENGINEERING - University of Pisa & $22 \%$ & $12.500 €$ \\
DII - University of Pisa & $4 \%$ & $2.500 €$ \\
DESTEC - University of Pisa & $16 \%$ & $9.000 €$ \\
University of Pisa & $5 \%$ & $3.000 €$ \\
\hline Total institutions & $47 \%$ & $\mathbf{2 7 . 0 0 0 €}$ \\
\hline \hline TOTAL RESOURCES & $\mathbf{1 0 0 \%}$ & $\mathbf{5 8 . 0 5 5} €$ \\
\hline
\end{tabular}

members have to manage several and unexpected situations and to find quickly the best solutions to the encountered problems. The team is bounded to work together to optimize time and to reach the best solutions, so each member is equally important for the success of the project. Students are supported by mentors of ESA that help and advise them in case of necessity. During the period of the experiment, some team members attended an intensive soldering course, specialized on space soldering, and they took part at a training week in which the teams heard lectures about all aspects of the REXUS/BEXUS programme.

U-PHOS project has an enormous scientific relevance, because it is directly connected to the work of the international scientific team on PHPs which is in charge to design the next PHP experiment for the International Space Station (ISS). Furthermore, due to the absence of gravity and its special design, the PHP has a bigger efficiency than Earth. These aspects make the experiment the beginning of a long term project that could lead to an implementation onboard of the ISS and in other space applications. Working on the project leads to a personal growth unreachable with a conventional academic course, because

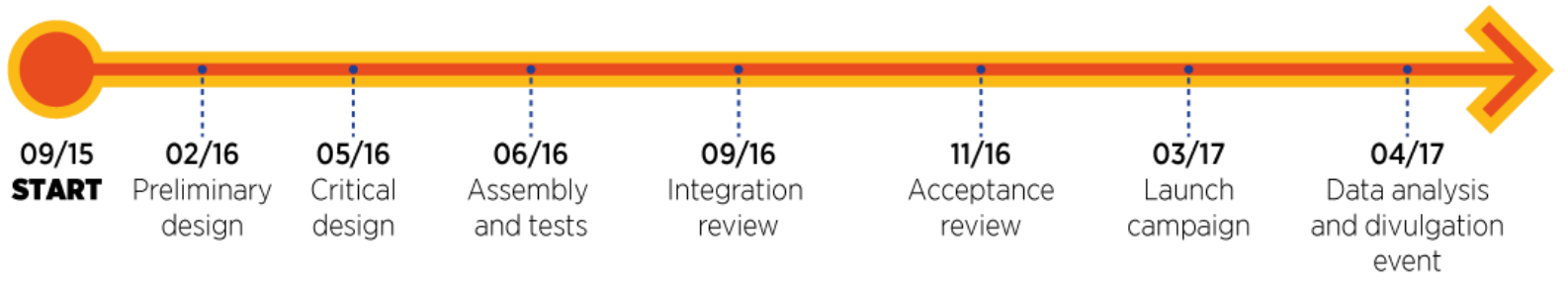

Fig. 4. Project timeline 
TABLE II. PHOS ALUMNI CAREERS

\begin{tabular}{|l|c|c|}
\hline \multicolumn{1}{|c|}{ ACTIVITY } & $\begin{array}{c}\text { NUMBER } \\
\text { OF } \\
\text { MEMBERS }\end{array}$ & $\begin{array}{c}\text { PHOS } \\
\text { RELATED } \\
\text { EXPERIENCES }\end{array}$ \\
\hline $\begin{array}{l}\text { Job in Selex ES } \\
\text { (Leonardo) }\end{array}$ & 2 & $\begin{array}{c}\text { PHP testing on } \\
\text { parabolic flight } \\
\text { PhD in Space } \\
\text { Communication }\end{array}$ \\
$\begin{array}{l}\text { Job position in other } \\
\text { companies }\end{array}$ & 1 & $\begin{array}{c}\text { Joined U-PHOS } \\
\text { project }\end{array}$ \\
PhD related PHPs & 3 & $\begin{array}{c}\text { PHP testing on } \\
\text { parabolic flight }\end{array}$ \\
Internship in ESA & 1 & $\begin{array}{c}\text { Joined U-PHOS } \\
\text { project }\end{array}$ \\
\hline
\end{tabular}

members have to organize themselves, find the necessary resources needed, mange project time and costs, all under the supervision and advice of the advisory professors.

During the project, the students learn by means of different methods, which are:

- $\quad$ Learn by doing

- Learn in a team

- Learn by competing

\section{B. Results}

Owing to the complexity of the experiment and the necessity of producing documentation, this kind of project is generally time consuming and requires much effort and dedication. For such reasons, by considering both the PHOS and U-PHOS members' experience, it is possible to estimate that this kind of experience produces an average increment of six months in the time necessary to complete the university path. However, thanks to the REXUS/BEXUS project, students can improve their technical skills, increase their relationships with industries and know new possibilities of internships and thesis. For those reasons, their careers are generally boosted by this kind of experience, especially in the aerospace field.

In Table II, careers of some PHOS project members are reported. In addition, several scientific publications (i.e. [3]) were produced after the conclusion of the PHOS project. A scientific publication has been produced [6] before the conclusion of the program.

\section{CONCLUSIONS}

The project, at the time we are writing, is still undergoing, precisely at the Experiment Acceptance Review phase. Even if the launch is scheduled in March 2017, the experiment is already fully built and integrated (Fig. 5), and it is already possible to assert that this experience, even if not completed, had an enormous impact on the students' career. By means of this paper, we expect to share our experience from an educational

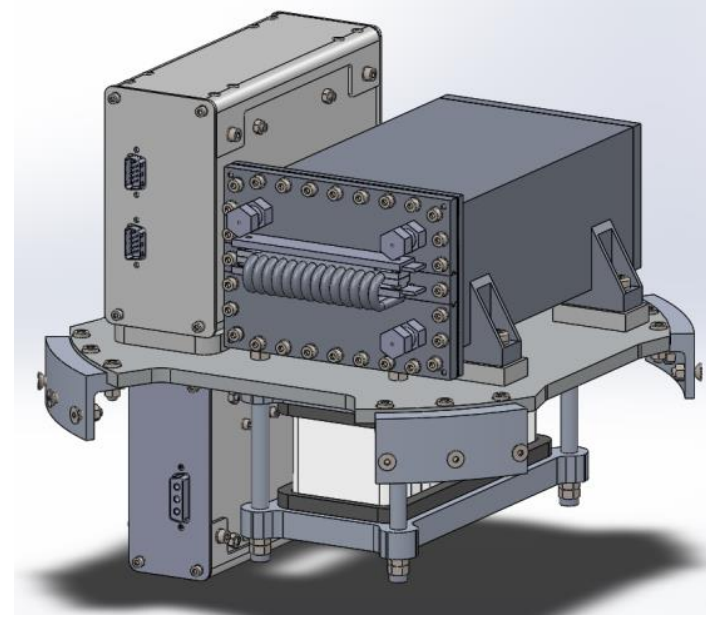

Fig. 5. U-PHOS Experiment

point of view and try to encourage participation in programmes like REXUS/BEXUS, which can definitely boost the students' career.

\section{ACKNOWLEDGMENT}

We would like to thank the many colleagues who supported us, even if they were outside of the team, just for the love of scientific research. We would also like to acknowledge ESA, DLR and SNSB, the ESA MAP INWIP project for funding the project, the International Scientific Team on Pulsating Heat Pipes, the school of engineering and AAVID Thermalloy, especially Marco La Foresta and Lorenzo Caporale, for the crucial help in the test cell manufacturing. We also would like to thank Alessandro Signorini and INFIBRA Technology for the great help.

\section{REFERENCES}

[1] F. J. Sánchez-Alejo, F. Aparicio, M. A. Álvarez and E. Galindo, "The developing of personal and professional skills in automotive engineers through university competitions" IEEE EDUCON 2010 Conference, Madrid, 2010, pp. 1491-1498.

[2] O. Persson, "REXUS/BEXUS - rocket and balloon experiments for university students" SpaceOps 2012 Conference, Stockholm, 2010

[3] M. Fittock, M. Siegl, A. Stamminger, M. Roth, H. Page, et al. "REXUS/BEXUS alumni - Looking at the long-term personal benefits of participation in a practical student programme" European Space Agency, (Special Publication) ESA SP, 700 SP, 2011, pp. 259-265.

[4] N. Callens, A. Kinnaird, K. Dannenberg, M. Fittock, M. Inga, et Al. "REXUS/BEXUS rocket and balloon experiments for university students" European Space Agency, (Special Publication) ESA SP, 721 SP, 2013, pp. 561-568.

[5] F. Creatini, G. M. Guidi, F. Belfi, G. Cicero, D. Fioriti, et Al. "Pulsating Heat pipe only for Space (PHOS): Results of the REXUS 18 sounding rocket campaign" Journal of Physics: Conference Series, 655 (1), art. no. 012042,2015

[6] P Nannipieri, M Anichini, L Barsocchi, G Becatti L Buoni, et Al. "UPHOS project: development of a large diameter pulsating heat pipe experiment on board REXUS 22", 34rd UIT Heat Transfer Conference, Ferrara (IT), July 4-6, 2016.

[7] ECSS-E-ST-10C - System engineering general requirements (6 March ) 